\title{
Papers
}

\section{Are coroners' necropsies necessary? A prospective study examining whether a "view and grant" system of death certification could be introduced into England and Wales}

\author{
G N Rutty, R M Duerden, N Carter, J C Clark
}

\begin{abstract}
Aims-To determine whether the cause of death could be accurately predicted without the need for a necropsy, and thus to consider whether a "view and grant" system of issuing a cause of death could be introduced into England and Wales.

Method-A one year prospective necropsy study was performed incorporating 568 deaths. Before necropsy, in each case the cause of death was predicted from the available history without examination of the body, and this cause was then compared with the cause of death found at necropsy.

Results-The ability of the pathologist involved in the study to predict a cause of death before necropsy, either while in the mortuary or as a paper exercise, was shown to vary between $61 \%$ and $74 \%$ of cases. After the necropsy, the number of correct predicted causes of death ranged from $39 \%$ to $46 \%$. Ischaemic heart disease was found to be the most common and most accurately predicted cause of death. Some natural diseases were frequently misdiagnosed, whereas certain types of unnatural disease were always identified correctly.

Conclusions-This study highlights the advantages and disadvantages of a view and grant system. Although it identifies a potential use of such a system, in some cases such as natural cardiac disease, because of the potentially high diagnostic error rate, the continuation of the present system of postmortem examination as part of the coroner's enquiry is recommended.

(F Clin Pathol 2001;54:279-284)
\end{abstract}

Keywords: necropsy; cause of death; coroner; view and grant

Over the past 40 years, despite many efforts, hospital necropsy rates throughout England and Wales have declined relentlessly. ${ }^{1}$ However, according to Home Office statistics, deaths reported to the coroner now account for a third of all deaths in England and Wales, having risen from 130000 in 1970 to 201000 in $1999 .^{2}$ Although this rise in referrals resulted in an increase of 12000 necropsies/year up to 1996 , there has been a corresponding fall in the number of coronial necropsies being performed in recent years. In $1999,62 \%$ of the total referrals underwent postmortem examination under the legal authority of the coroner. ${ }^{3}$ This differs from Scotland and other parts of the world where a "view and grant" system of death certification exists. ${ }^{45}$ In Scotland, $24 \%$ of deaths are referred at present to the procurator fiscal, with $41 \%$ undergoing postmortem examination.

Throughout this century the value of the necropsy for diagnosis, teaching, research, and statistical data collection has been debated within the literature, although most of this work relates to hospital necropsies, and not to those performed for medicolegal purposes. ${ }^{6-22}$ However, in this day of increasing public concern related to necropsies-for example, retention of tissue, local budget restraints, and recently potential issues of human rights - the question for the need to perform a coronial necropsy upon those dying within the community of apparently natural causes is continuously and rightly questioned.

The aim of our study was to assess whether the cause of death could be predicted accurately, without the need for a necropsy, based on the clinical information available to the pathologist at the time of the necropsy in persons dying predominately in the community. We will discuss whether the results support the adoption of a view and grant system in England and Wales or whether this practice in Scotland and other parts of the world results in potential misdiagnoses of causes of death.

\section{Method}

A one year prospective study was undertaken at the Medico-Legal Centre, Sheffield between the months of March 1997 and March 1998. Most necropsies performed in this period, all of which were requested under the legal authority of Her Majesty's Coroner, were incorporated 
Table 1 Details of the numbers of estimated causes of death and numbers of correct diagnoses for each pathologist (A-C) at each stage of our study

\begin{tabular}{|c|c|c|c|c|c|c|c|c|}
\hline & $\begin{array}{l}\text { Total no. of } \\
\text { necropsies } \\
\text { performed/ } \\
\text { pathologist }\end{array}$ & $\begin{array}{l}\text { No. of causes of } \\
\text { death predicted } \\
\text { before necropsy }\end{array}$ & $\begin{array}{l}\text { No. of correct } \\
\text { causes of death }\end{array}$ & $\begin{array}{l}\text { No. of causes of } \\
\text { death predicted as } \\
\text { a paper exercise }\end{array}$ & $\begin{array}{l}\text { No. of correct } \\
\text { causes of death as } \\
\text { a paper exercise }\end{array}$ & $\begin{array}{l}\text { No. of total cases } \\
\text { predicted }\end{array}$ & $\begin{array}{l}\text { No. of total correct } \\
\text { causes of death }\end{array}$ & $\begin{array}{l}\text { Total no. of correct } \\
\text { diagnosis for all } \\
\text { cases }\end{array}$ \\
\hline $\mathrm{A}$ & 155 & $144(93 \%)$ & $74 / 144(52 \%)$ & $228 / 413(55 \%)$ & $165 / 228(72 \%)$ & $372 / 568(65 \%)$ & $261 / 372(70 \%)$ & $261 / 568(46 \%)$ \\
\hline B & 141 & $84(60 \%)$ & $38 / 84(45 \%)$ & $265 / 427(62 \%)$ & $165 / 283(58 \%)$ & $349 / 568(61 \%)$ & $219 / 349(63 \%)$ & $219 / 568(39 \%)$ \\
\hline $\mathrm{C}$ & 118 & $98(83 \%)$ & $36 / 98(37 \%)$ & $322 / 450(72 \%)$ & $182 / 322(57 \%)$ & $420 / 568(74 \%)$ & $248 / 420(59 \%)$ & $248 / 568(44 \%)$ \\
\hline Others & 154 & - & - & - & - & - & - & - \\
\hline Total & 568 & - & - & - & - & - & - & $568(100 \%)$ \\
\hline
\end{tabular}

into our study. These comprised predominately natural deaths in the community, although a small proportion of hospital deaths requiring coronial necropsies were included. Frankly suspicious or homicidal deaths were excluded from our study.

Before each necropsy, the pathologist read a report that had been produced by either the police officer or a coroner's officer. This report provided all known information concerning the deceased at the time of the necropsy including their age, occupation, circumstances surrounding the death, and medical history, including drug history, where available. Where the death had occurred in hospital, the medical notes were made available before the necropsy. In all cases, a coroner's officer had previously spoken to a medical practitioner either known to the deceased or from the medical practice with which the deceased was associated. This was to assess whether a death certificate could be issued without the need for a necropsy, and if not, to elaborate upon the medical history before the necropsy.

In each case, before the necropsy, the pathologist decided whether they felt they could predict a cause of death solely from the written information available. This was written on to a proforma in the same format as a death certificate. Guidance was given to the pathologist with regard to the wording of the predicted cause of death. They were requested to use the same phraseology for the predicted prenecropsy cause of death that they anticipated that they would use for the post-necropsy cause of death.

It was decided by the participants of the study that viewing of the body, which is part of a view and grant system, would not be performed before the prediction of the cause of death. This was done to assess whether viewing really was an essential component of the view and grant system or whether the information available on the sudden death report of death was sufficient to predict the cause of death.

After the necropsy, the pathologist recorded the final cause of death on to the proforma. The circumstances surrounding the death and the medical history, but not the age and occupation, were photocopied and attached to the proforma and stored until the end of the study period. Any additional information concerning the deceased, which subsequently became available after the necropsy, was not included, because this could have caused bias in the second part of the assessment.

The forms were separated into four groups, according to who performed the necropsy. The three largest groups comprised necropsies performed by three lead pathologists (GR, NC, JC) with the fourth group composed of other pathologists who had performed a smaller number of necropsies during the study period. Where necropsies had been performed by one of the three lead pathologists, the photocopies of the medical history and circumstances of the death were given to the other two lead pathologists to predict the cause of death so that each case had predictions made by all three lead pathologists. Because this was a paper exercise based on clinical information only, again no viewing of the body took place. In the fourth group of cases, where a pathologist had performed a necropsy and filled out a prediction of the cause of death but was not further involved in the study, all original predictions were discounted and the cases were assessed by the three lead participants as a paper exercise only. Therefore, in all cases in our study, a cause of death was predicted by the three lead pathologists, either as a paper exercise or in the mortuary. In each case, the prediction was compared with the real cause of death by one independent assessor, $\mathrm{RD}$, who had not been involved during the necropsies or paper assessment.

The data were collated using the computer statistical program SPSS ${ }^{\circledR}$. Comparisons were made for each case regarding whether each pathologist could predict a cause of death from the information available and, if so, whether the prediction was correct. A predicted cause of death was only deemed to be correct if the immediate and underlying causes of death were the same as for the post-necropsy cause. Assessment as to whether a prediction was correct or not was made difficult by the different nomenclature of specific diseases used by the different pathologists involved, and also because of the complex nature of mortality data coding, used as a guideline for categorising causes of death. Where discrepancies occurred, a note was made as to whether these were small or large according to the ICD 9 classification (differences were small if the underlying cause of death was within the same numerical subgroups). Disease contributing to death, but not causing it (that is, information in part 2 of the formal cause of death), was not included in our study. The frequencies of correct predictions and minor and major discrepancies with different causes of death were recorded.

\section{Results}

A total of 610 cases had a prediction of the cause of death made before the necropsy. Forty two cases were subsequently discounted because of insufficient information or unavailability of records. This gave a total study 
Table 2 Top 10 groups of most common causes of death following necropsy

\begin{tabular}{llll}
\hline & Disease & No. of cases & $\begin{array}{l}\text { Percentage of } \\
\text { total cases }\end{array}$ \\
\hline 1 & Ischaemic heart disease & 207 & 36 \\
2 & Hypertensive heart disease/hypertensive and ischaemic & 46 & 8 \\
& $\quad$ heart disease & 39 & 7 \\
3 & Myocardial infarction & 29 & 5 \\
4 & Ruptured aortic aneurysm & 28 & 5 \\
5 & Pulmonary thromboembolism & 20 & 4 \\
6 & Haemopericardium owing to ruptured myocardial infarct & 18 & 3 \\
7 & Overdose of medication & 17 & 3 \\
8 & Bronchopneumonia & 8 & 1 \\
$9 / 10$ & Subarachnoid haemorrhage & 8 & 1 \\
& Hanging & \\
\hline
\end{tabular}

population of 568 cases. Of these, 75 categories of causes of death were used, of which eight were unnatural (36 deaths $(6.3 \%)$ ).

Of the 568 cases, $414(73 \%)$ necropsies were performed by one of the three lead pathologists (A, 155; B, 141; and C, 118 cases), with the remaining 154 cases performed by seven other pathologists. The ability of the three lead pathologists to predict a cause of death at all before necropsy varied from one pathologist to another: A predicted $93 \%$, B predicted $60 \%$, and $\mathrm{C}$ predicted $83 \%$. The number of correct predictions based upon the final outcome of the necropsy also varied between pathologists: A predicted $52 \%$ correctly, B predicted $45 \%$ correctly, and $\mathrm{C}$ predicted $37 \%$ of cases correctly (table 1).

When the three lead pathologists were asked to predict a cause of death as a paper exercise on the patients in whom they had not performed necropsies, the ability to predict a cause of death again varied: $55 \%$ for $\mathrm{A}, 64 \%$ for $\mathrm{B}$, and $72 \%$ for $\mathrm{C}$. This exercise now included the necropsies performed by the other seven pathologists. Again, the number of correct predictions of the cause of death where a prediction was offered showed individual variation: $72 \%$ for A, $58 \%$ for B, and $57 \%$ for C.

When all cases were considered, the total number of cases where a predicted cause of death was offered was: $65 \%$ for A, $61 \%$ for B, and $74 \%$ for C. Allowing for minor differences in the wording of the cause of death, the number of correct predictions made of those where a cause of death had been proffered were as follows: A, $70 \%$; B, $63 \%$; and C, $59 \%$. Thus, when we analyse whether a prediction could by proffered in the first place and then whether the diagnosis made was correct, the total percentage of correct diagnoses made by each lead pathologist for all cases was: A, $46 \%$; B, $39 \%$; and C, $44 \%$.

Three causes of death had $100 \%$ correct prediction rates for all consultants in all cases; carbon monoxide poisoning, hanging, and malignant mesothelioma, which accounted for 16 cases in total (3\%). However, in some cases no predictions were made by any of the consultants, usually because the report had insufficient or irrelevant information concerning the circumstances surrounding the death. The most frequently diagnosed cause of death was ischaemic heart disease (IHD), accounting for 207 of the total study cases $(36 \%)$. Of these cases, $68.7 \%$ were predicted to have died from
IHD and $71.3 \%$ of these predictions were correct. Table 2 lists the top 10 groups of diseases found to be the cause of death after necropsy. These accounted for 420 cases $(74 \%)$, with the remaining 148 cases $(76 \%)$ falling into the other 66 categories of causes of death. It was noteworthy that three causes of death, namely bronchopneumonia, pulmonary thromboembolism, and ruptured aortic aneurysm (all of which occur in table 2), were frequently misdiagnosed; of the 74 cases in these groups, only 12 cases $(17 \%)$ were predicted correctly during our study.

\section{Discussion}

In common with "hospital" (consent) postmortem examinations, the number of necropsies performed under the legal authority of the coroner has shown a recent slight decline (1996, 67.7\%; 1999, 62\%). It must be questioned whether all of the coronial necropsies performed are necessary or whether fewer should be performed, but to a higher standard. Our study highlights the fact that most of the cases examined here died as a result of natural diseases and came to the attention of Her Majesty's Coroner because the circumstances surrounding the death placed them into one of the notifiable groups. ${ }^{23}$ Many of these deaths are reported because the deceased's own general practitioner felt unable to issue a certificate, or because the deceased had not been seen by the certifying doctor either after death or in the 14 days before.

It has been debated within the medical literature previously whether hospital necropsies remain necessary, the argument revolving around the perceived primary purpose of the necropsy, to identify the cause of death. In the case of the hospital necropsy, some clinicians argue that, using diagnostic skills and modern investigative methods - for example, imaging devices - they are confident that in most cases they could identify the major disease from which the patient was suffering, and which is likely to be the cause of death. Pathologists, however, are quick to point out that there are several publications emphasising that the pathological findings might differ greatly from the clinical impression in between $3 \%$ and $68 \%$ of cases (table 3). ${ }^{24-65}$ Considering these previous publications, if the clinicians' hypothesis was correct, then one might expect a decline in the reported proportion of diagnostic errors over the years as diagnostic techniques have improved. However, as demonstrated in table 3 this does not seem to be the case. Medical personnel frequently forget that in the case of a hospital necropsy, the establishment of the cause of death is not necessarily the primary objective, there also being an important role in teaching and research, with the opportunity to assess disease progression and treatment.

To date, there are very few publications related to the perceived and real cause of death in those dying in the community. This, in part, is related to how each country deals with the investigation and certification of death. Even within the UK, two different systems exist, namely: referral to Her Majesty's Coroner in 
Table 3 Percentage of diagnostic errors identified at necropsy in previously published postmortem studies 1919-98

\begin{tabular}{|c|c|c|c|}
\hline Ref. & First author & Year & $\begin{array}{l}\text { Percentage of major } \\
\text { discrepancies/alternative } \\
\text { cause of death (\%) }\end{array}$ \\
\hline 24 & Karsner & 1919 & 68 \\
\hline 25 & Swartout & 1940 & 21 \\
\hline 26 & Wallgren & 1945 & 49 \\
\hline 27 & Munck & 1952 & 20 \\
\hline 28 & Borris & 1952 & 33 \\
\hline 29 & James & 1955 & 48 \\
\hline 30 & Gruver & 1957 & 6 \\
\hline 31 & Justin-Besencon & 1963 & 30 \\
\hline 32 & Otterland & 1964 & 28 \\
\hline 33 & Wilson & 1966 & 47 \\
\hline 34 & Heasman & 1966 & 55 \\
\hline 35 & Holler & 1970 & 3 \\
\hline 36 & Britton & 1974 & 30 \\
\hline 13 & Burrows & 1975 & 11.9 \\
\hline 6 & Cameron & 1980 & 42 \\
\hline 9 & Anderson & 1984 & 10 \\
\hline 14 & Kircher & 1985 & 29 \\
\hline 37 & Stevanovic & 1986 & 29 \\
\hline 38 & Battle & 1987 & 33.8 \\
\hline 7 & Ferdandez-Segoviano & 1988 & 10 \\
\hline 39 & Karwinski & 1989 & 12 \\
\hline 40 & Carvalho & 1991 & 36 \\
\hline 41 & Stambouly & 1993 & 28 \\
\hline 42 & Teo & 1993 & 54 \\
\hline 43 & McKelvie & 1993 & 12 \\
\hline 44 & Veress & 1993 & 27 \\
\hline 45 & Veress & 1994 & 15 \\
\hline 46 & Szende & 1994 & 43 \\
\hline 47 & Manzini & 1995 & 42 \\
\hline 48 & Goldstein & 1996 & 12 \\
\hline 49 & Kendrey & 1996 & 59 \\
\hline 50 & Zehr & 1997 & 20 \\
\hline 51 & Blosser & 1998 & 21 \\
\hline 52 & Burton & 1998 & 44 \\
\hline 53 & Ermenc & 1999 & 13.5 \\
\hline
\end{tabular}

England and Wales and to the procurator fiscal in Scotland, with the option of view and grant. With the view and grant system, the pathologist is provided with all the available medical history, as well as the circumstances of the death, and performs a thorough external examination of the naked body. If the pathologist is then satisfied that the death is the result of a natural cause they can issue a death certificate, without the need for a full postmortem examination. This system is not confined to Scotland and occurs in several countries within Europe.

If this system works both within part of the UK and other countries of the world, the question must arise as to whether it would be appropriate to introduce such a system into England and Wales. This might reduce the number of coroner's necropsies performed on those dying of natural causes in the community, but might give rise to considerable errors in assessing the real cause of death, which may have important public health implications. Studies in Texas (USA) and the Scandinavian countries of Finland, Denmark, and Sweden estimate diagnostic errors of between $1 \%$ and $77 \%$ of cases between the perceived cause of death by view and grant and the real cause of death on subsequent necropsy. ${ }^{66-71}$ Such reported figures do not immediately instil faith in the view and grant system.

Our study highlights several important points when considering whether or not a view and grant system might be appropriate for England and Wales. The first is whether or not the pathologist feels able to predict a cause of death before necropsy. This appears to be dependent upon several factors, the most important of which is the quality of information available to the pathologist. Although this appears to be obvious, it has been shown previously that the quality of information available might at times be less than optimal and, therefore, the pathologist might be unable to issue a cause of death in the same manner in which a general practitioner may not be able to do so. ${ }^{72}$ The two parts of our study highlight this point. The ability of one lead pathologist to predict a cause of death was reduced from $93 \%$ to $55 \%$ when the age and occupational history of the deceased was withheld in the paper exercise, although this posed less difficulty to the other two lead pathologists.

Our study shows that, depending upon the pathologist performing the necropsy and whether the cause was predicted in the mortuary or as a paper exercise, between $61 \%$ and $74 \%$ of cases had a predictable cause of death. This indicates that during the study period up to $39 \%$ of the cases would still potentially have had to have a necropsy. This finding also raises questions as to why, when the same information that the pathologist had was available to the deceased's medical practitioner, who might also have had personal knowledge of the patient, that practitioner was not in a position to issue a death certificate, whereas the pathologist felt that there was sufficient information available in up to $74 \%$ of cases. There are several possible explanations for this, which have not been specifically investigated in our study but include the " 14 day rule" ${ }^{\text {"23 }}$ and other more simple explanations, such as the deceased's own medical practitioner being absent from the practice (for example, on holiday) and nobody else from the practice being in a position to issue a certificate.

The next issue that arises from our study is that even if the pathologist were able to predict a cause of death, would this cause be correct as identified by postmortem examination? Our study suggests that ultimately between 39\% and $46 \%$ of predicted causes had a correct diagnosis, most of which were cardiac related. Thus, if a view and grant system were available, although it would reduce the number of necropsies performed, in those in which a necropsy was not carried out $54-61 \%$ of the diagnoses would be incorrect. This figure falls within the range noted above from other countries and raises important questions over the accuracy of such a system.

It could be criticised that our study is not a true view and grant system because no examination of the body was performed before the estimation of the cause of death. However, this was omitted on purpose, because the primary function of viewing the body is to examine it for suspicious marks which, if present, would necessitate a full postmortem examination. The omission of this aspect of view and grant did not deter the pathologists from predicting a cause of death. With the exception of a pulmonary thromboembolism, which might be identified from swelling of the legs, none of the other natural diseases in the top 10 causes of death (table 2) would be 
expected to show any signs externally. Therefore, viewing the body should make little difference to the ability to decide a cause of death.

Finally, if we consider unnatural causes of death within the community-for example, carbon monoxide poisoning, hanging, and overdoses as well as industrial disease such as malignant mesothelioma - the pathologists had no trouble in making the diagnosis before the necropsy, even though all of the cases still had to be investigated under the rules of referral to Her Majesty's Coroner. This differs from some other countries where a proportion of these deaths - for example, from hanging — would be certified without necropsy.

Although our study does give some support to the view that, given an adequate clinical history and knowledge of the circumstances surrounding the death, a view and grant system could be used in England and Wales, particularly in natural, cardiac related illness, it highlights that there is still a potential for a diagnostic error rate of between $54 \%$ and $61 \%$ of cases. Therefore, we consider that necropsies still have an essential role within the coroner's enquiry, an enquiry that must answer four questions, namely: who the person was, and where, when, and how they came by their death. It must also be considered that if a pathologist could predict the correct cause of death with greater certainty then fewer necropsies would be required. This would allow valuable time and resources to be directed towards those deaths truly requiring postmortem investigation, thereby increasing the value and possibly the quality of necropsies performed within England and Wales. By whom and where these necropsies should be performed was not within the scope of our study, although these questions should be considered together with other aspects of the investigation of natural and unnatural deaths.

1 Cameron HM. Future of the hospital autopsy. Fournal of Hospital Medicine 1998;40; 335.

2 Brindle NPJ, McCarthy MJ, Bell PRF. The coroner service. A relic in need of reform. BMF 1999;318:1502-3.

A relic in need of reform. BMF 1999;318:
Home Office statistical bulletin. Issue 8/00.

4 Davison AM, McFarlane JH, Clark JC. Differences in forensic pathology practice between Scotland and England. Med Sci Law 1998;38:283-8.

5 Dorzynski A. French doctors miss out on postmortem examinations. BMf 1997;315:503.

6 Cameron HM, McGoogan E, Watson H. Necroscopy: a yardstick for clinical diagnosis. BMF 1980;281:985-8.

7 Fernandez-Segoviano P, Lazaro A, Esteban A, et al. Autopsy as quality assurance in the intensive care unit. Crit Care Med 1988;16:683-5.

8 McPhee SJ, Bottles K. Autopsy: moribund art or vital science? Am f Med 1985;78:107-13.

9 Anderson RE. The autopsy as an instrument of quality assessment. Classification of premortem and postmortem assessment. Classification of premortem and postmortem diagnostic

10 Open Forum. A debate on the autopsy: its quality control function in medicine. Hum Pathol 1974;5:605-18.

11 Peacock SJ, Machin D, Duboulay CEH, et al. The autopsy: a useful tool or an old relic? F Pathol 1988;156:9-14

12 O'Sullivan JP. The coroner's necropsy in sudden death: an under-used source of epidemiological information. $\mathcal{F}$ Clin Pathol 1996;49:737-40.

13 Burrows S. The postmortem examination. Scientific necessity or folly? $\mathcal{F A M A} 1975 ; 233: 441-3$

14 Kircher T, Nelson J, Burdo H. The autopsy as a measure of accuracy of the death certificate. $N$ Engl $\mathcal{F}$ Med 1985;313: 1263-9.

15 Belzberg H, Rivkind A. It always pays to make the diagnosis: to autopsy or not to autopsy. Crit Care Med 1998;26:1299300 .

16 Clark MA. The value of the hospital autopsy. Is it worth the cost? Am f Forensic Med Pathol 1981;2:231-7.
17 Goldman L, Sayson R, Robbins S, et al. The value of the autopsy in three medical eras. $N$ Engl f Med 1983;308: autopsy in

18 Charlton R. Autopsy and medical education: a review. $\mathcal{f} R$ Soc Med 1994;87:232-6.

19 Lowry F. Failure to perform autopsies means some MDs "walking in a fog of misplaced optimism". Can Med Assoc 7 1995;15:811-14.

20 Smith CJ, Scott SM, Wagner BM. The necessary role of the autopsy in cardiovascular epidemiology. Hum Pathol 1998; 29:1469-79.

21 Prutting J. Lack of correlation between antemortem and postmortem diagnoses. New York State fournal of Medicine 967;2081-2084

22 Kingsford DPW. A review of diagnostic inaccuracy. Med Sci Law 1995;35:347-51.

23 OPCS guidance on referral. Circular letter from departmental chief medical statistician. In: Dorries, ed. Coroner's courts. A guide to law and practice. London: Wiley, 1996:283-7.

24 Karsner HT, Rothschild L, Crump ES. Clinical diagnosis as compared with necropsy findings in six hundred cases. AAMA 1919;73:666.

25 Swartout HO, Webster RG. To what degree are mortality statistics dependable? Am f Public Health 1940;30:811.

26 Wallgren I. Obduktionsfyndet och de liniska dignoserna. Nord Med 1945;26:1311.

27 Munck W. Autopsy findings and clinical diagnosis. A comparative study of 1000 cases. Acta Med Scand 1952;266(suppl):775.

28 Borris W. Die Bedeutung der Verwaltungssektion fur die Morbiditats-und Mortalitatsstatistik. Z Arztl Fortbild (fena) 1952;46:471.

29 James G, Patton RE, Helsin AS. Accuracy of cause-of-death tatements on death certificates. Public Health Rep 1955;70: 39.

30 Gruver RH, Freis ED. A study of diagnostic errors. Ann Intern Med 1957;47:108.

31 Justin-Besencon L, Chretien J, Delavierre P. Communication. Bilan de 1000 confrontations anatomocliniques recentes. Bull Acad Natl Med 1963;147:330.

32 Otterland A, Pihl E. Klinisk, Patologisk-anatomisk och officiell dodsorsaksdiagnostik med utgangspunkt fran 327 obduktionsfall. Lakartidningen 1964;61:68.

33 Wilson RR. In defence of the autopsy. $f A M A$ 1966;196: 1011.

34 Heasman MA, Lipworth L. Accuracy of certification of cause of death. London: HMSO, 1966.

35 Holler JW, Morgan NP. A retrospective study of 200 post-mortem examinations. Fournal of Medical Education $1970 ; 45: 168-70$

36 Britton M. Diagnostic errors discovered at autopsy. Acta Med Scand 1974;196:203-10

37 Stevanovic G, Tucakovic G, Dotlic R, et al. Correlation of clinical diagnoses with autopsy findings: a retrospective study of 2,145 consecutive autopsies. Hum Pathol 1986;17: $1225-30$.

38 Battle RM, Pathak D, Humble CG, et al. Factors influencing discrepancies between premortem and postmortem diagnoses. $7 A M A 1987 ; 258: 339-44$

39 Karwinski B, Hartveit F. Death certification: increased clinical confidence in diagnosis and lack of interest in confirmation by necropsy is not justified. $\mathcal{F}$ Clin Pathol 1989;42:13-17

40 Carvalho FM, Widmer MR, Cruz M, et al. Clinical diagnosis versus autopsy. Bull Pan Am Health Organ 1991;25:416.

41 Stambouly JJ, Kahn E, Boxer RA. Correlation between clinical diagnoses and autopsy findings in critically ill children. Pediatrics 1993;92:248-51.

42 Teo CES. A study of coroner's cases from hospitals: a comparison of autopsy and clinical diagnosis. Annals Academy of Medicine 1993;22:3-7.

43 McKelvie PA. Medical certification of causes of death in an Australian metropolitan hospital. Med f Aust 1993;158: $816-21$

44 Veress B, Alafuzoff I. Clinical diagnostic accuracy audited by autopsy in a university hospital in two eras. Quality Assurance in Health Care 1993;5:281-6.

45 Veress B, Alafuzoff I. A retrospective analysis of clinical diagnoses and autopsy findings in 3,042 cases during two different time periods. Hum Pathol 1994;25:140-5.

46 Szende B, Kendry G, Lapis K, et al. Accuracy of admission

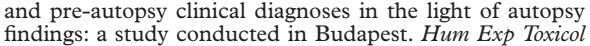
1994;13:671-80.

47 Manzini VP, Revignas MG, Brollo A. Diagnosis of malignant tumor: comparison between clinical and autopsy

48 Goldstein B, Metlay L, Cox C, et al. Association of pre mortem diagnosis and autopsy findings in pediatric intensive care unit versus emergency department versus ward patients. Crit Care Med 1996;24:683-6.

49 Kendrey G, Szende B, Lapis K, et al. Misdiagnosis of lung cancer in a 2000 consecutive autopsy study in Budapest. Gen Diagn Pathol 1995/96;141:169-78.

50 Zehr KJ, Liddicoat JR, Salazar JD, et al. The autopsy: still important in cardiac surgery. Ann Thorac Surg 1997;64: $380-3$.

51 Blosser SA, Zimmerman HE, Stauffer JL. Do autopsies of critically ill patients reveal important findings that were clinically undetected? Crit Care Med 1998;26:1332-6. 
52 Burton EC, Troxclair DA, Newman WP. Autopsy diagnoses of malignant neoplasms. How often are clinical diagnoses incorrect? $f A M A$ 1998;280:1245-8.

53 Ermenc B. Minimizing mistakes in clinical diagnosis. $\mathcal{F}$ Forensic Sci 1999;44:810-13

54 Cameron HM, McGoogan E. A prospective study of 1152 hospital autopsies: II. Analysis of inaccuracies in clinical diagnoses and their significance. $\mathcal{F}$ Pathol 1981;133:285300 .

55 Hartveit F. Clinical and post-mortem assessment of the cause of death. F Pathol 1977;123:193-210.

56 Robinson IA, Marley NJE. Factors predicting cases with unexpected clinical findings at necropsy. F Clin Pathol unexpected clinical

57 Riboli E, Delendi M, Gardiman D, et al. Comparison between diagnoses of cancers of the stomach, colon, rectum, gall-bladder, liver and pancreas on death certificates and at autopsy in Trieste, 1970-84. In: Riboli E, Delendi M, eds. Autopsy in epidemiology and medical research. Lyon: IARC, 1991:45-54

58 Delendi M, Riboli E, Peruzzo P, et al. Comparison of diagnoses of cancers of the respiratory system on death certificates and at autopsy. In: Riboli E, Delendi M, eds. Autopsy in epidemiology and medical research. Lyon: IARC, 1991:5562.

59 Di Bonito L, Santa G, Delendi M, et al. Comparison between diagnoses on death certificates and autopsy report in Trieste: gynaecological cancers. In: Riboli $\mathrm{E}$, Delendi $\mathrm{M}$, IARC, 1991:63-71.

60 Grundmann E, Menke GG. Autopsy diagnosis versus clinical diagnosis, particularly in malignant disease. Comparison of two periods: 1961-70 and 1978-87. In: Riboli E Delendi M, eds. Autopsy in epidemiology and medical research. Lyon: IARC, 1991:81-90.

61 Rossi S, Grandi R, Grandi E. Correlation of clinical diagnosis with autopsy findings. In: Riboli E, Delendi M, eds. Autopsy in epidemiology and medical research. Lyon: IARC, 1991:99-108.
62 Tsujimura T, Yamada Y, Kubo M, et al. Why couldn't an accurate diagnosis be made? An analysis of 1044 consecutive autopsy cases. Pathol Int 1999;49:408-10.

63 Mort TC, Yeston NS. The relationship of pre mortem diagnoses and post mortem findings in a surgical intensive care unit. Crit Care Med 1999;27:299-303.

64 Hasuo Y, Ueda K, Kiyohara Y, et al. Accuracy of diagnosis on death certificates for underlying causes of death in a long-term autopsy-based population study in Hisayama, Japan; with specific reference to cardiovascular disease. $\mathcal{F}$ Clin Epidemiol 1989;42:577-84.

65 Mollo F, Bertoldo E, Grandi G, et al. Reliability of death certification for different types of cancer. An autopsy survey. Pathol Res Pract 1986;181:442-7.

66 Asnaes S, Paaske F. The significance of medicolegal autopsy in determining mode and cause of death. Forensic Sci Int 1979;14:23-40.

67 Segerberg-Konttinen M. Determination of cause and mode of death before and after medicolegal autopsy: a comparative study. F Forensic Sci 1988;33:441-7.

68 Asnaes S, Paaske F. Uncertainty of determining mode of death in medico-legal material without autopsy-a systematic autopsy study. Forensic Sci Int 1980;15:3-17.

69 Asnaes S. Uncertainty of determining mode and cause of death without autopsy: an autopsy study of medically unattended non-medicolegal deaths. Forensic Sci Int 1980;15: 191-6.

70 Gerdin B, Lindquist O. Comparison between predicted cause of death and cause of death found at autopsy in medicolegal autopsy material. Z Rechtsmed 1980;85:181-7.

71 Vanatta PR, Petty CS. Limitations of the forensic external examination in determining the cause and manner of death. Hum Pathol 1987;18:170-4.

72 Sampson H, Carter N, Rutty GN. Information before the coronial autopsy: how much should be available? $\mathcal{f}$ Clin Pathol 1999;52:581-7.

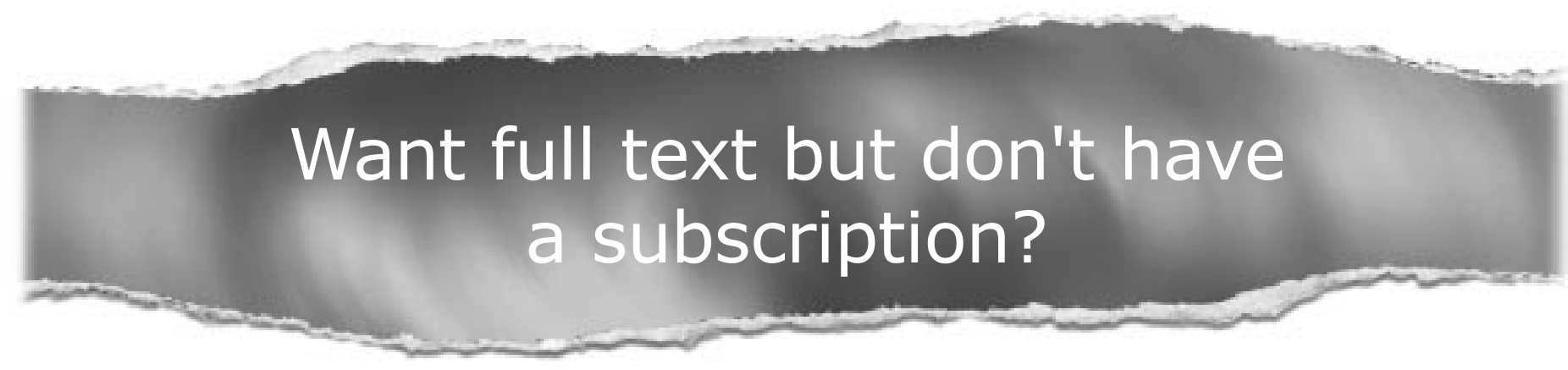

Pay per view

For just $\$ 8$ you can purchase the full text of individual articles using our secure online ordering service. You will have access to the full text of the relevant article for 48 hours during which time you may download and print the pdf file for personal use.

\section{wwW.jclinpath.com}

